\title{
Borana women's indigenous social network-marro in building household food security: Case study from Ethiopia
}

\author{
Abiyot Eliyas Anbacha* and Darley Jose Kjosavik
}

\begin{abstract}
Pastoralist societies, including Borana, are known for their strong social networks, which provide social- and livelihood-related functions. This paper explores the role of marro - women's social security network in accessing resources to overcome household food security in Borana, southern Ethiopia. The paper investigates types of resources shared and the role of shared resources in augmenting household food security. The study employed individual interviews, group interviews, focus group discussions and field observations to generate data among two communities engaged in pastoral and agro-pastoral production systems. Results show marro is a voluntary social support network between friends, neighbours and families in which all women participate, regardless of livelihood bases, economic status and age differences. The majority of women use marro when need arises, while a significant number of poor and elderly women depend on it for daily survival. Marro relations resemble both bonding and bridging networks in which resources are mobilized and shared between neighbouring and far-distant households respectively. In both bonding and bridging marro, women share resources such as food items, labour and cash on the basis of trust and solidarity. The primary aim of the shared resources is to overcome household food shortages that increase during drought. However, increases in drought combined with lack of proper external support are limiting the scope of marro in building household food security by limiting the availability of resources and increasing the number of poor people demanding help that need serious attention. The findings of this study add knowledge on the role of social security networks in improving household food security that must be taken into consideration for designing responsive and sustainable food security programmes and projects in pastoral areas in general and Borana in particular.
\end{abstract}

Keywords: Social network, Marro, Women, Food security, Borana, Ethiopia

\section{Introduction}

People in traditional societies practise different types of informal social support institutions for survival. For example, peasants have a strong belief in the right to subsistence security which is maintained through social networks of reciprocity (Scott 1976). As communities living with livelihood uncertainties, pastoralists engage in mutual assistance through various forms of social networks (Dahl and Hjort 1979). The term 'social capital' is often used in literature to describe such social relations. Social capital encompasses social networks, norms and trust that enable

\footnotetext{
* Correspondence: abiyot.anbacha@gmail.com

Department of International Environment and Development Studies, Norwegian University of Life Sciences (NMBU), Ås, Norway
}

members to act together to achieve shared objectives (Putnam 1993).

The literature on social capital has classified social networks derived from reciprocity into two categories: bonding social capital and bridging social capital (Putnam 2000; Woolcock 2001). Bonding is an intra-community relation among defined socioeconomic groups based on kinship and friendship, whereas bridging is an inter-community relation between people of different identities but having common aims (Brunie 2009; Pelling and High 2005; Putnam 2000). Bridging ties enable the sharing of resources and opportunities in one network with members in other networks (Granovetter 1973). Bonding creates strong, dense network structures, involves strong social norms and develops localized trust between 
members (Newman and Dale 2005). Both social bonding and bridging improve social wellbeing by establishing fundamental trust between groups (Aldrich et al. 2016) which largely represent a social insurance system against risks (Aktipis et al. 2011).

Such networks are widely practised by pastoralist and agro-pastoralist societies in East Africa. A few among many of these networks are the age-based resource distribution known as Rendille in north Kenya (Sato 1984, 1997), Mutual Help of Maasai of Tanzania (Gray and Mueller 2012; Potkanski 1999), the Stock Friend network of Turkana (Vries et al. 2006) and Kinship Support busagonfa ${ }^{1}$ of Borana (Tache and Sjaastad 2008). The primary aim of these social security networks is to overcome household food shortage, alleviate food insecurity and smooth consumption (Aktipis et al. 2011; Stavropoulou et al. 2017). Other functions of social networks are to reduce hunger and meet other basic needs (Platteau 1991) through goods exchanged (Aktipis et al. 2011; Johnson 1999; Kazianga and Udry 2006; Stavropoulou et al. 2017). More specifically, the food-sharing culture among pastoralist women is to overcome household food shortages (Stavropoulou et al. 2017). In addition, women's networks increase their access to resources and reduce the existing gender gap (Khalif 2010). In general, the stock of social networks, including that of women, determines the degree to which vulnerability is reduced, including household food shortage, and opportunies appear in the community (Moser 1998).

Despite the significance of the social security networks in improving household food shortage and ensuring survival, they largely remained invisible in formal policy and programmes towards building food security and reducing poverty (Agrawal et al. 2009; Devereux and Getu 2013), owing partly to limited studies available on the role of the networks. However, it is impossible to understand food security and vulnerability in isolation of the cultural context of the daily experiences of women and men in building household food security (Tolossa 2009). Moreover, better understanding of the networks enables design of formal programmes on the basis of local understandings that in turn build trust and meet the needs and priorities of women and men. In the same manner, due attention can make the networks evolve that in turn builds strong communities (Moser 1998). Therefore, by focusing on Borana women's social network, this study aims to fill a knowledge gap on the role of social networks, particularly that of women, in building household food security.

Borana people are one of the well-known pastoralist groups living in southern Ethiopia and northern Kenya. They belong to the Oromo ethnic group that largely lives in Ethiopia. They speak Afan Oromo, ${ }^{2}$ a language belonging to the Cushitic family. Borana people's culture is constructed around complex social networks that serve both social- and livelihood-related functions. The social networks help Borana to share available resources including food items and other resources to ensure survival during hard times (Oba 2001; Tache and Sjaastad 2008; Tiki et al. 2010). Some of the networks among the Borana are gender-specific; exclusively for women, like marro (Tache and Sjaastad 2008). However, the role of the networks, including that of women, has not got enough attention and is even ignored in formal food security programmes and other development projects operating in the Borana area. Thus, this study aims to investigate the role of marro - women's social security network - in accessing livelihood resources for building household food security. Particularly, the study aims to answer first, the nature and frequency of women's participation in marro; second, types of resources shared in marro and third, the role of shared resources in building household food security. For the study, both pastoral and agro-pastoral production systems were examined to understand how the bonding and the bridging networks of marro function to build household food security.

\section{Study area}

The Borana Oromo ethnic group lives in northern Kenya and southern Ethiopia. This study was undertaken in the Borana zone of southern Ethiopia (Figure 1). Borana zone is generally characterized as arid and semi-arid with fluctuating climatic conditions and mean annual rainfall between 400 and $600 \mathrm{~mm}$ (Coppock 1994). Pastoralism is the main livelihood, and the people are generally referred as cattle herders, and also they keep sheep, goats and camels (Bassi and Tache 2007; Tiki et al. 2010).

Though the Borana system was once viewed as the most sustainable type of pastoralism, currently, it is under increased vulnerability (Desta and Coppock 2004) resulting from recurring droughts as well as socio-economic and political factors. The people are known for their strong social security networks of helping each other during hard times including droughts (Tache and Sjaastad 2008). In addition, to overcome climate and non-climate stressors, Borana pastoralists are increasingly diversifying their livelihoods (Abebe 2016; Hertkorn et al. 2015; Tache and Oba 2008). The diversified livelihoods shift the economy from pastoral towards agro-pastoral production. However, in other areas of the zone, some of the communities are still predominantly pastoralist. Thus, the selection of study communities is informed by this livelihood dynamics, to know if there is a difference on the use of marro in different production systems.

\section{Methods}

We selected two pastoralist associations for this study: one predominantly pastoralist and the other agro-pastoralist. 


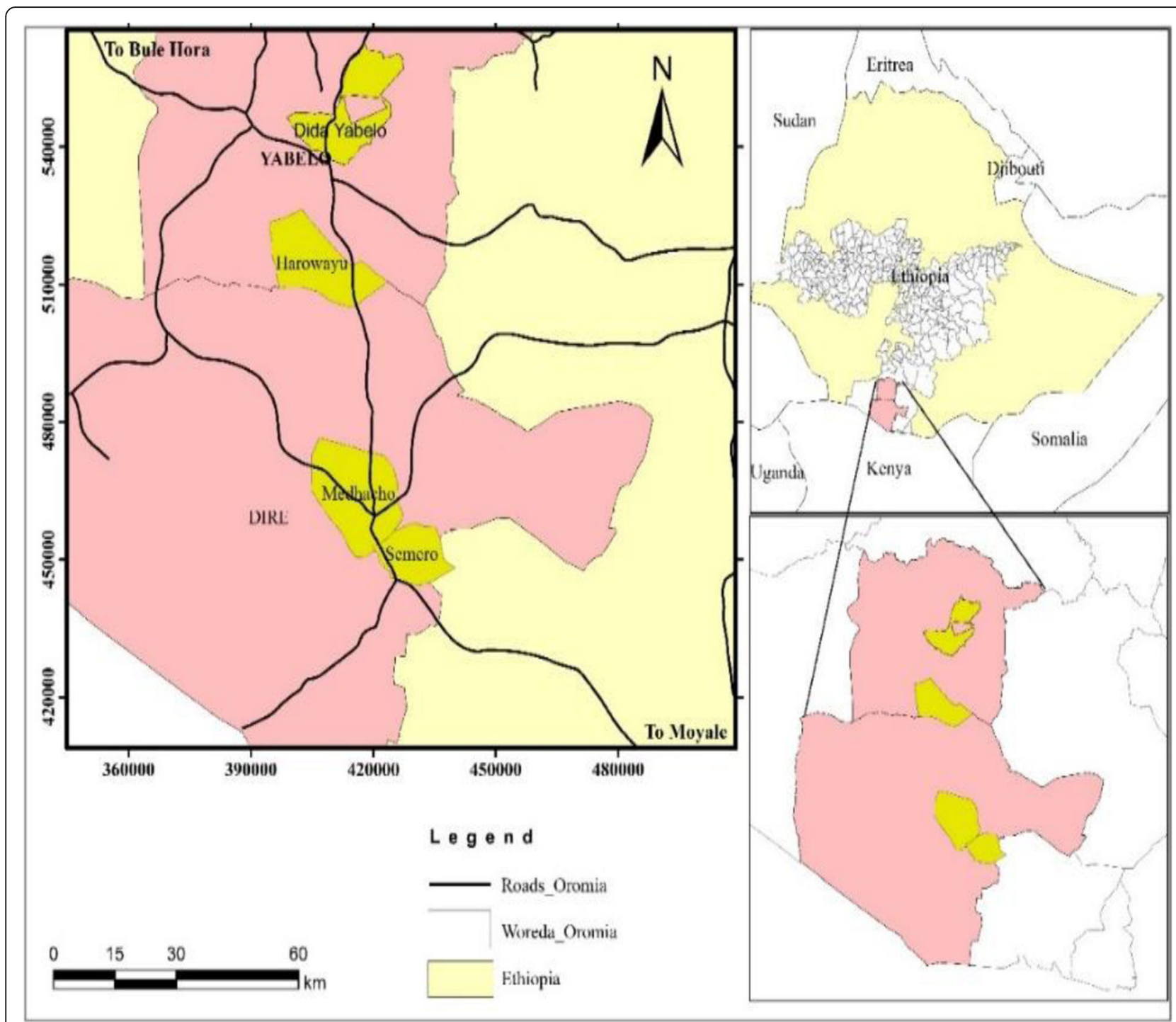

Figure 1 Map of Borana zone. This figure indicates the location of the study area. Borana zone is basically divided into 13 districts, and each district has subdivided into pastoral and agro-pastoral communities organized as pastoralist associations (PAs)

Pastoralist associations are the smallest unit of adminstration in the area. After settling pastoralists the government had organized them into pastoral associations within districts. The agro-pastoralist livelihood is more diversified with a mix of crop production, herding activities, poultry farming, livestock trading, petty trading and sale of forest products (Anbacha and Kjosavik have an unpublished manuscript of an in-depth study of livelihood diversification of the Borana). However, this does not mean communities in the pastoral production system never participate in non-pastoral activities. For instance, every Borana household has a small plot of land up on which they produce crops.

For this study, two pastoralist associations (Harowayu and Madacho PAs) representing both production systems were selected. The Harowayu pastoralist association was selected to represent the pastoral production system. The settlement pattern of Harowayu shows households grouped into different villages and the households are close to each other. The Madacho pastoralist association was selected to represent agro-pastoral livelihoods. Communities in Madacho practise animal trade, petty trade and crop production along with pastoralism. The households are located on the main road from Addis Ababa to Moyale.

From the selected two pastoralist associations, for individual interviews, we randomly selected 64 women respondents: 32 from the pastoral and 32 from the agro-pastoral production systems. In this study, we used the traditional wealth ranking system of Borana people that depend on the number of cattle the households own. In Borana wealth ranking system, the 
Table 1 Individual interview respondents

\begin{tabular}{ll}
\hline Respondent category & Total count \\
\hline Pastoralist association & 32 \\
Harowayu & 32 \\
Madacho & 64 \\
Total & \\
Economic status & 34 \\
Poor (dega) & 20 \\
Self-sufficient (offi-danda'an) & 10 \\
Rich (duressa) & 64 \\
Total & \\
Age & 34 \\
Young (18 to 35 years) & 20 \\
Middle age (36 to 50 years) & 10 \\
Old (above 50 years) & 64 \\
Total &
\end{tabular}

households that own zero to five cattle are considered as 'poor' (locally termed dega), from five to ten cattle considered as 'just self-sufficient' (offi-danda'a) and above ten are considered as 'rich' (duressa). Here, each group is independent of each other. The detailed information of the respondents is given below (see Table 1).

Data on women's participation in marro, types of resources shared and the role of shared resources in household food security were collected from both communities using individual interviews. The individual interviews were face-to-face, using a structured questionnaire with the selected women respondents. Apart from individual interviews, four group interviews with women sharing the same marro, and two focus group discussions, were conducted, to collect data on frequently shared resources, factors affecting participation and the importance of shared resources in building household food security. Group interviews were conducted with women in the same marro to understand how each of them participate and use marro. In the group interview, the group size was small (three to five women) and the meetings were of short duration (about an hour for each group). On the other hand, in the focus group discussions women in different marro participated. In each focus group discussion, nine to 12 women participated, which indicates the relatively big group size, and each session lasted for two to three hours. The focus group discussions were in the form of detailed discussions among the women on specific topics, in contrast to the group interview where data are collected in the form of question-and-answer.

In order to answer the first question on participation, the selected women were individually asked to respond to a structured questionnaire prepared in Afan Oromo. The women were asked to rate their participation in marro by choosing between 'daily basis', 'occasionally', and 'once in a while'. In this study, 'daily basis' was used for women who depend on marro for everyday survival, while 'occasionally' for those who use marro whenever there is a need arises, whereas 'once in a while' are for those women who use marro rarely - only when there are no other alternatives to meet their needs. Most of the time, these women meet their needs by themselves and request help 'once in a while'. They usually have other alternatives for meeting their needs and only use the network 'once in a while' when they do have no other means. For instance, a woman who has cash can buy things she needs rather than going to her marro group women. This is common among rich women. In addition, in the focus group discussions and group interviews, women were asked to define and describe marro. In the study, we considered sharing of resources with immediate neighbours as bonding, and across communities as bridging network.

In order to answer the second question on types of resources shared in marro, the women were asked during the group interviews and focus group discussions to list, categorize and describe major resources shared in both bonding and bridging marro. In addition, in individual interviews, the women were also asked to state the category of resources they shared most often in their relations. The third question, the role of marro in ensuring household food security, was answered by allowing the women to sit down in groups and discuss the primary purpose of shared resources, and the role of these resources in improving household food security and challenges of marro. In addition, women in individual interviews were asked to choose if shared resources have no impact, positive impact and negative impact on household food security.

The study mainly employed qualitative data analysis. Content analysis was used to analyse and interpret data from group interviews, focus group discussions and observations. Data collected from individual interviews were entered into SPSS software version 22 and run for descriptive statistics-cross tabulation for the analysis. For the comparisons between groups such as livelihood base, age and wealth status, chi-square test was used.

\section{Results}

\section{Marro and the participation of women}

Group interviews indicated that the word marro was derived from its Afan Oromo root word called marru, meaning to round or to move in a circle. This shows that marro's function is to round all households in times of difficulty. The women stated that 'future is uncertain for all', in that a household with no problem today may face challenges in the future, for which the household might seek help from friends, relatives and 
neighbours through marro relations. As per their discussion, 'giving today is akin to putting aside resources as an insurance for tomorrow's problems'. Therefore, the giver is happy to invest in the neighbour's household, for which she expects a return during her own difficulties.

All participants in individual interviews stated that marro is an informal institution and has no formal rules or leaders. Similarly, the qualitative information also supports this idea. Information from group interviews and focus group discussions stated that the functioning of marro is based on the societal value of helping each other and expressing solidarity. As determined in a study which indicated that trust was a primary feature of social networks (Ostrom and Ahn 2001), there is a fundamental trust between women in Borana. The women discussants stated that the strong belief of Borana society in interdependence. This is indicated in Borana sayings: wanti Borani qabu kan borana hundati meaning 'whatever an individual Borana owns belongs to all Borana'. This ensures the smooth functioning of marro at different levels.

As indicated in the group interviews, marro is established between near-distance households within a village and also between far-distant communities engaged in different production systems. The former is established between neighbouring households and has the bonding nature of a social network as an intra-community relationship. The bonding depends on the general rule of the society, stating that villagers have strong obligations to help each other. The Borana saying (stated by one informant) 'olla fi dudan dhabatu', meaning villagers and backbone make you to stand straight, indicates the importance of villagers (bonding) in the life of the society. This relationship of marro enables households to access available resources within their own communities to meet household needs, particularly food requirements for survival. Bonding marro provides households in crisis with immediate and regular support as indicated in the qualitative information. Resources are exchanged more frequently in this relation compared to bridging marro. In marro relations established between neigbouring households resouces are exchanged frequently contrary to relations between far distant families.

Bridging marro is an inter-community relationship that links the households in different production systems, as indicated in focus group discussions. This enables households in a pastoral production system to access resources of households in agro-pastoral communities and vice versa. This is similar to the finding that bridging networks enable sharing of resources in one area with members in another area (Granovetter 1973). Compared to bonding marro, sharing is less frequent in this relationship; however, resources shared in bridging relations are relatively better in quantity and quality, as stated by women during discussion. This is due to the differences in livelihood portfolios between the households. In general, both bonding and bridging ties of marro coordinate and promote cooperation between households to achieve their objectives. This is similar to a study finding that social norms and trust enable participants in the institution to pursue and achieve their common objectives together (Moser et al. 2010). The bonding and bridging nature of marro between households is presented in a diagram (see Figure 2).

Regardless of livelihood basis, age or economic background, all women participate in marro (see Table 2). This finding is similar to the results of a study undertaken in northern Kenya among Waso Borana women (Khalif 2010). Although all women have marro, the rate of participation varies between women in different production systems, economic status and age groups.

Pure pastoralist community

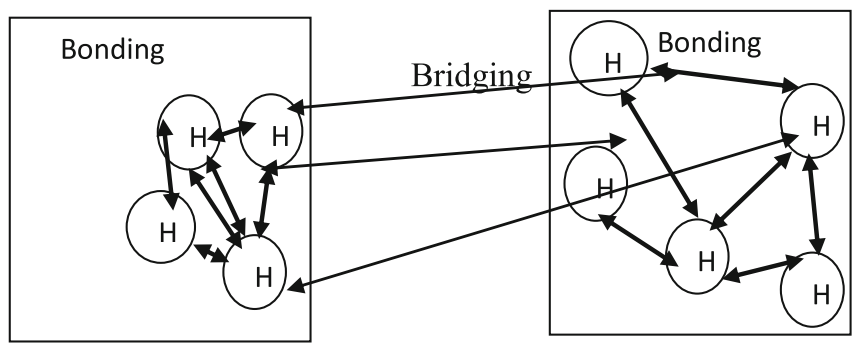

Figure 2 A conceptual representation of marro. In this figure, bonding marro is depicted by the thick arrows showing the strong relations between neighbouring households. There are many bonding marro within the same village. A woman can be a member of different marro. She can also choose over different marro in her village. In marro, women exchange gifts of different items frequently to meet the needs of the households. The bridging marro links pastoral and agro-pastoral communities for sharing resources. Contrary to bonding, bridging marro established between communities spatially separated or in different locations. Thus, bridging marro relation links communities in different locations to ensure survival through sharing available resources. In this case, pastoral women establish marro with agro-pastoral women and share their livestock products such as milk, meat, butter and yoghurt in return for grains from agro-pastoral women that enable them to address household food deficit 
Table 2 Participation of women in marro

\begin{tabular}{|c|c|c|c|c|c|c|c|c|c|c|}
\hline \multirow[t]{2}{*}{ Participants } & \multirow[t]{2}{*}{ Total count } & \multicolumn{2}{|c|}{ Do you participate? } & \multicolumn{4}{|c|}{ Level of participation } & \multicolumn{2}{|c|}{ Chi-square } & \multirow[b]{2}{*}{ Sig. } \\
\hline & & Yes \% & No $\%$ & Once in a while & Occasionally & Daily & Total \% & Value & $\mathrm{df}$ & \\
\hline \multicolumn{11}{|l|}{ Livelihood } \\
\hline Pastoralism & 32 & 100 & & 5 & 70 & 25 & 100 & & & \\
\hline Agro-pastoralism & 32 & 100 & & 10 & 65 & 25 & 100 & & & \\
\hline Total & 64 & 100 & & & & & & & & \\
\hline \multicolumn{11}{|l|}{ Wealth status } \\
\hline Poor & 34 & 100 & & 0 & 62 & 38 & 100 & 44.418 & 4 & 0.0001 \\
\hline Self-sufficient & 20 & 100 & & 0 & 93 & 7 & 100 & & & \\
\hline Rich & 10 & 100 & & 30 & 60 & 10 & 100 & & & \\
\hline Total & 64 & 100 & & & & & & & & \\
\hline \multicolumn{11}{|l|}{ Age groups } \\
\hline Young & 34 & 100 & & 6 & 69 & 25 & 100 & 12.579 & 4 & 0.014 \\
\hline Middle aged & 20 & 100 & & 12 & 69 & 19 & 100 & & & \\
\hline Old & 10 & 100 & & 0 & 62 & 38 & 100 & & & \\
\hline Total & 64 & 100 & & & & & & & & \\
\hline
\end{tabular}

Source: Fieldwork data, 2015

However, statistical analysis revealed that there is no significant variation between women in pastoral and agro-pastoral production systems in terms of the frequency of their participation in marro. This study also indicates that economic status is the determinant factor for women's participation in marro. Within the wealthy category, the majority of women participate in marro occasionally. Statistical analysis on the participation of women in marro indicated that there is significant variation on the basis of their economic status at $\left(p=0.0001, \chi^{2}=\right.$ $44.418, \mathrm{df}=4$ ). For instance, $93 \%$ of self-sufficient women participate occasionally whereas none of women in this group participate only rarely 'once in a while'.

Of all groups, a relatively high percent of women (30\%) in rich households participate only 'once in a while'. This indicates there is less participation among rich women or less dependency of rich women on marro. This differs from a previous study, which indicated a high participation of wealthy women in their marro relationships (Oba 2001). The reason for this difference between these two studies lies in the way the questions were framed. In this study, the focus was on how often women are using marro to overcome their problems, while the previous study's focus was on how often women are helping others in the relation. Compared to other women, a significant number of poor women (38\%) depend on marro for daily survival.

The qualitative information from all group interviews supports this finding that the economic status of women determines their dependence on marro, as poor women depend more on marro for daily survival. They establish marro with rich women, in which the poor women provide labour, and in return receive resources needed in their households. One of the young pastoralist informants described her own situation as follows:

I am a very poor woman and I do not have cattle. I provide labour for my neighbours for which I get the items needed for my household's daily. I depend on this relation regularly. [A poor young woman].

Although poor women are more dependent on marro, usually they have less expansive marro networks than rich women, as indicated in group discussions. In Borana, having expansive marro is a sign of respect, while not having marro is an insult, as indicated in the discussions. Therefore, every woman wants to have strong and expansive marro. However, economic status combined with the generosity behaviour of the woman determines her marro size. The discussants further explained that women in rich households build strong and expansive marro by investing more resources in the relationship. Similarly, those who invest more in relationships also get more support in times of their need. The discussants strongly emphasized that investment is vital for the smooth functioning of marro, noting that a lack of resources makes marro inactive and dormant. This is similar to a previous study in Kenya (Oba 2001). One of the discussants described how her low economic situation negatively affected her marro:

I had wide marro in the past; however, drought in 2011 that killed my cattle limited my participation 
in marro. Increase in household poverty prevented me from investing in my marro. Since then, most of the time I only receive resources more than giving to my marro women, that further inactivate my relation. I have already lost some of my previous marro women [a poor middle-aged woman pastoralist].

The discussants added that generosity $\left(\right.$ toltu $\left.^{3}\right)$ is the other important asset which determines the expansiveness of a woman's marro. They stated that a rich but hamtu ${ }^{4}$ woman (someone who does not want to share her resources with others) has usually limited marro.

Similar to women in poor households, a significant number of old women (38\%) depend on marro for daily survival. There is a significant variation $\left(p=0.014, \chi^{2}=12.579\right.$, $\mathrm{df}=4$ ) between women of different age groups in the rate of their participation in marro. Information from the group interviews confirms the finding that marro provides regular support for old women. These women cannot go far to fetch water, collect firewood and fodder and thus depend on others' labour. The old women establish marro with a young woman in which the elder serves as babysitter, prepares food and cleans hut and surroundings, while her marro young woman goes to the market, collects firewood and fetches water as indicated in women's group discussions. She shares the items brought from outside with the old woman who provided her with help/labour. One of the informants stated her own experience as follows:

I am an old woman and I cannot go to market, collect firewood and fodder. You see this boy [indicating a small boy sitting on her lap], I am taking care of him, he is my neighbour's son and his mother went to market. She will come with sugar and salt. This is how we live in Borana. My marro young women are helping me in providing things needed and I also help them in taking care of kids, clean house and provide tea when they come back from outside [an old woman from agro-pastoralist community].

In addition, the discussants mentioned that there are certain specific circumstances such as sickness, death and giving birth, in which all women need daily help from their marro women. As per the Borana culture, a woman soon after giving birth is entitled to rest for seven weeks (49 days). During this period, she is not allowed to exert herself in any activity including food preparation, taking care of children, going to market, collecting firewood, fetching water, washing clothes and other chores. This applies to all women irrespective of economic status, age and presence or absence of someone to help her in the household. If she has someone such as a mother-in-law or other women relatives, the burden on her marro decreases; otherwise, her marro women are responsible for all her household activities. In such circumstances, all women who have just given birth need help from their marro daily for a limited period. During data collection in Harowayu, we met a young woman who had given birth less than three weeks ago. She explained her dependence on marro:

I gave birth and I am entitled to rest and only responsible to feed my new baby. Other kids are with my marro woman, she is caring for them. Others brought me water, see [pointing to a container full of water], some come with firewood and food [a young woman].

The same is true if the woman is sick and unable to do her household chores. One of the informants explained her experience as follows:

I got bad injury on my leg three weeks ago while I was collecting firewood. Since then I am sick, and in bed. I cannot fetch water, collect firewood and go to market. For all these days, my marro women are providing needed goods and services for my household. Some of them bring me food, others provide labour; if I do not have them it would have been very hard for my family [a middle-aged woman].

Borana women are applying their marro relation in different circumstances that made the role of the institution quite complex. As indicated in the discussions, women are using marro in different situations including child birth, child naming ceremony, marriage, sickness and death, in addition to improving household food security to access the necessary resources for the households in different situations.

\section{Resources shared in marro}

In the group interviews and focus group discussions, women listed major resources shared in bonding and bridging relations of marro (Table 3 ).

Resources shared in marro include milk, butter, yogurt, meat, bones, tobacco, tea leaves, sugar, salt, labour, firewood, water, grains and cash categorized as food items, labour and cash. Among these, both food items and labour are widely shared between women of different livelihoods, age groups and different wealth statuses (Table 4). This study indicated that majority of pastoral women (79\%) share food items and labour in their marro. Resources shared in both production systems vary, although majority mainly share food items and labour. 
Table 3 Qualitative information on resources shared in marro

\begin{tabular}{|c|c|c|}
\hline Resource category & Resources shared & Description \\
\hline \multirow[t]{4}{*}{ Food } & Milk, butter, yoghurt & $\begin{array}{l}\text { Commonly shared in bonding and bridging, especially in } \\
\text { bridging women in pastoral livelihood share with } \\
\text { agro-pastoral women }\end{array}$ \\
\hline & Meat and bones & $\begin{array}{l}\text { Household slaughters animal share meat and bones. } \\
\text { Women in the household are responsible to share these } \\
\text { with her marro women. The bone sharing is very common } \\
\text { during drought crises where well-to-do households are } \\
\text { expected to share with poor households to ensure survival. }\end{array}$ \\
\hline & Cooked food & $\begin{array}{l}\text { Mostly shared in bonding, women share with neighbouring } \\
\text { households in most cases. This can be given as immediate } \\
\text { support to households. Any person coming across cooked } \\
\text { food has full right to eat, even if not a member of the family. } \\
\text { It is also shared within bridging marro rarely. }\end{array}$ \\
\hline & Salt, sugar, tea leaves and tobacco & $\begin{array}{l}\text { These are commonly shared in bonding marro. Neighbouring } \\
\text { households share these resources more frequently. }\end{array}$ \\
\hline \multirow[t]{6}{*}{ Labour } & Firewood, water & $\begin{array}{l}\text { Women collect firewood for each other in marro. Commonly } \\
\text { shared in bonding relation can also be shared in bridging } \\
\text { during ceremonies. Common to bring for sick women and } \\
\text { new mothers. }\end{array}$ \\
\hline & Fodder & $\begin{array}{l}\text { Increasingly shared than ever before. Women collect fodder } \\
\text { in collective through marro, becoming very popular with } \\
\text { increases in drought leading to animal feed shortage. }\end{array}$ \\
\hline & Going to market & $\begin{array}{l}\text { Women also combine their activities to overcome labour } \\
\text { shortage through marro. A woman going to market buys } \\
\text { the things needed by neighbouring households while the } \\
\text { one at home undertakes household activities. }\end{array}$ \\
\hline & Preparing food & $\begin{array}{l}\text { Other important activity for which women use bonding } \\
\text { marro. It is common to prepare food for households when } \\
\text { woman in the household is sick, gave birth or has some } \\
\text { special programmes. }\end{array}$ \\
\hline & Hut-making & $\begin{array}{l}\text { Hut-making is usually undertaken by marro. Hut-making in } \\
\text { the face of drought for a single woman is very hard. } \\
\text { That is why women use their relation to make huts for each other. }\end{array}$ \\
\hline & Farming activities & $\begin{array}{l}\text { Women are undertaking farming activities such as land-clearing, } \\
\text { weeding, harvesting and transporting in marro. During drought } \\
\text { when men move with animals, women do many of the farming } \\
\text { activities through marro relation. }\end{array}$ \\
\hline \multirow[t]{2}{*}{ Cash } & Loan & $\begin{array}{l}\text { Cash loan is newly introduced resources in marro and increasing } \\
\text { these days. Women give each other loans for purchase of foodstuffs } \\
\text { or for undertaking business. Most of the loans are simple and easy } \\
\text { to pay has no interest. }\end{array}$ \\
\hline & Gift & $\begin{array}{l}\text { Women also give to each other in their relation a cash gift. This is } \\
\text { not in the form of a loan but as a gift from marro woman. }\end{array}$ \\
\hline
\end{tabular}

In agro-pastoral communities, more women share food and labour; however, a significant percentage also share the three varieties of resources: food, labour and cash. Similarly, based on production system, further statistical analysis portrayed a significant variation between women at $\left(p=0.028, X^{2}=9.096, \mathrm{df}=3\right)$ on resources shared in their relationships. This shows that livelihood basis is a significant factor determining the variety of resources shared in the women's relationships. As indicated in all group interviews, the more diversified the livelihood of the household, the more variety of resources shared in marro. The group interviews with agro-pastoralist women showed that their engagement in crop farming had increased the variety of resources shared in marro, in such a way that using grains from crop farming strengthens their marro with pastoral women. This shows diversification has increased the variety of resources women share in their institution.

In terms of economic status, the majority of rich women use a greater variety of resources in their relations, whereas nearly all (97\%) of the poor share mainly labour and food items in such a way they provide labour to marro women for which they receive food items. Although many of the poor households generally depend on food aid for daily survival, they are investing part of the aid to activate their marro as indicated in the focus group discussions. It 
Table 4 Respondents sharing different resources in marro

\begin{tabular}{|c|c|c|c|c|c|c|c|c|c|}
\hline \multirow[t]{2}{*}{ Participants } & \multirow[t]{2}{*}{ Total count } & \multicolumn{5}{|c|}{$\%$ of respondents sharing different resources } & \multicolumn{3}{|c|}{ Chi-square } \\
\hline & & $\begin{array}{l}\text { Food and } \\
\text { labour }\end{array}$ & $\begin{array}{l}\text { Food and } \\
\text { cash }\end{array}$ & $\begin{array}{l}\text { Labour } \\
\text { and cash }\end{array}$ & $\begin{array}{l}\text { Food, cash } \\
\text { and labour }\end{array}$ & Total\% & Value & df & Sig. \\
\hline \multicolumn{10}{|l|}{ Production system } \\
\hline Pastoralist & 32 & 79 & 0 & 6 & 15 & 100 & 9.096 & 3 & 0.028 \\
\hline Agro pastoralist & 32 & 47 & 6 & 3 & 43 & 100 & & & \\
\hline Total & 64 & & & & & & & & \\
\hline \multicolumn{10}{|l|}{ Economic status } \\
\hline Poor & 34 & 97 & 0 & 0 & 3 & 100 & 42.78 & 6 & 0.0001 \\
\hline Self-sufficient & 20 & 35 & 5 & 10 & 50 & 100 & & & \\
\hline Rich & 10 & 0 & 0 & 10 & 90 & 100 & & & \\
\hline Total & 64 & & & & & & & & \\
\hline \multicolumn{10}{|l|}{ Age group } \\
\hline Young & 34 & 76 & 3 & 9 & 12 & 100 & 16.63 & 6 & 0.011 \\
\hline Middle aged & 20 & 35 & 5 & 0 & 60 & 100 & & & \\
\hline Old & 10 & 70 & 0 & 0 & 30 & 100 & & & \\
\hline Total & 64 & & & & & & & & \\
\hline
\end{tabular}

Source: Fieldwork data, 2015

is true that there is no formal linkage between marro and food aid programmes as indicated in the qualitative information, but informally women are investing it in their marro relationships. Thus, this strengthens their marro relation by availing food items to be shared.

Information from group interviews and focus group discussions in both production systems indicated that food items are the most commonly shared resources, followed by labour. This is similar to the study finding that local networks pool foodstuffs and other resources to overcome the suffering of the people (Agrawal et al. 2009). As discussed by the women, they share food in different circumstances. Women in households where there is food shortage access the needed food through marro. Similarly, if a woman has a visitor or guest and she does not have food to give the guest, she sends a messenger (ergamitu), usually a child, to her marro woman, to send sugar, tea leaves or any other foodstuff she needs for her guest. The marro woman gives what she has, not only from her surplus but also from limited resources, to help the woman and to maintain her good image in the eyes of the visitor. This was observed during the interviews. In one case, in the Harowayu settlement, when our interviewee had a visitor from Yabello, this gave us an opportunity to see first-hand information how marro applied to overcome household food shortage through sharing resources. Our interviewee did not have tea leaves and sugar in her own house to prepare tea for the guest (as was the custom in the community). She excused herself and went to her neighbour who supplied her with the required ingredients and she was then able to serve her guest. For the discussants, labour is the second most commonly shared resource. They stated that Borana women bear a disproportionate burden of household domestic roles including cooking, fetching water, collecting firewood, cleaning, hut-making, going to market and taking care of children and the sick. Moreover, increases in droughts have added to the work burden of the already busy women by extending the time needed to collect firewood and fetch water. In order to overcome the common labour shortage, even under normal circumstances, many women combine some

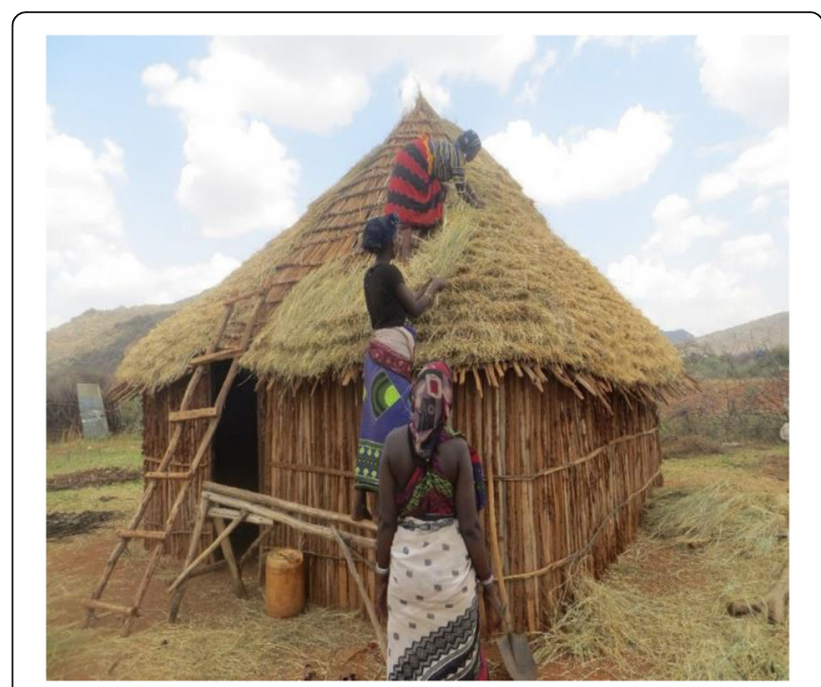

Figure $\mathbf{3}$ Women making hut in marro. This figure is a picture taken in Harowayu pastoralist association while women in marro are constructing a hut or house for their marro woman. A woman and her marro cut trees and covering grasses and bring these to the location where she and her marro are making the hut together, with no involvement of husbands 
of their work with their marro women. For example, a woman going to a market buys the items needed for her marro women, while the women at home take care of household activities, and other women go to fetch water and collect firewood that they share between needy households who helped them to save time and energy. The other major activity Borana women use marro for is hut-making (see Figure 3). Here, the women make huts together in order to reduce time and energy needed.

Although this study revealed the involvement of cash in marro, information from focus group discussions and group interviews indicated that cash was not part of the resources shared in marro relations in the past. The introduction of cash into current marro has two forms; cash is given as a gift and and as a loan, explained the discussants. If a woman approaches her marro woman for certain items and the requested woman also does not have the items but has some cash, she gives the cash to buy the items needed. This type of cash is not a loan; rather, it is a gift from marro woman. The woman who benefited from the cash is not expected to repay it; instead, she will do the same for her marro woman in times of need.

A study undertaken in northern Kenya poses questions concerning the moral value of introducing cash as a loan in marro (Khalif 2010). However, women in this study are using the cash loan from marro relation for different purposes, including food purchases and for business. Most of the time, the loan from marro does not bear interest and has no maturity period; instead, the borrower repays the loan when she gets money. If she cannot repay for a genuine reason, she has the possibility of asking for debt relief. As per the discussants, the introduction of cash in marro was as a result of the current pastoral transformation which has increased cash accessibility.

\section{Roles and challenges of marro in building household food security}

Regardless of the livelihood basis, economic status and age differences, all individual informants confirmed that marro has a positive impact on ensuring household food security. Similarly, participants' group interviews and focus group discussions added that resources shared in marro directly or indirectly contribute to household food security improvement; according to the discussants, the primary objective of sharing resources in both bonding and bridging marro is to overcome household food shortages. The shared resources, particularly food items are never sold or changed to other forms, but aimed to increase food availability of distressed households.

The elderly women interviewees stated Borana pastoralists were food-secure and that the people had enough cattle to provide milk and milk products, which were staple foods of the society in the past. According to these women, milk production per cow was higher than it is currently. If two or more cows were in the milking period, they give surplus milk. The excess milk was used to feed young calves. Even in well-to-do households where there were large numbers of cows, some of the cows were not milked. In those past days, our informants told us, Borana pastoralists share food items for love and affection rather than as form of security.

In more recent times, food has become a critical problem for the Borana following several devastating droughts, as indicated in all group interviews and focus group discussions. In Borana households, women become more responsible for ensuring household food requirements as men have increasingly lost their entitlements due to droughts. In order to meet the food requirements of the household, women use marro to access food from near and far-distant households. Although women share food items under normal circumstances, during drought, they increasingly share what they have for survival. This is similar to a study which concluded that social capital plays critical roles during drought crises (Aldrich and Meyer 2015). In marro, women share limited food items available to ensure that everyone has something to eat. The discussants added that if food is available in one household, people in the next household never go to bed with empty stomachs'. It is indeed part of the culture to share available resources among Borana women, to survive as a community. Thus, marro as social capital is one of the important sharing cultures among women that helped hard-pressed households to access food. This is corroborated by a study carried out after Hurricane Katrina in USA, which found that connections across social, cultural and economic lines provides access to essential resources like food for families (Aldrich et al. 2016). It is common practice for people to use their social institutions in order to overcome difficulties. One of the poor women in the group interview explained the existing sharing philosophy as Borani yoo nyate anis nan-nyadha, which means if a Boran ${ }^{5}$ (individual Borana) eats, I will eat' indicating in the Borana community, everyone is entitled to food without any preconditions.

Borana women understand each other's food shortages and feel a responsibility to fill the gap, sometimes even before help is requested. However, it is also the right for a hard-pressed woman to request food from her marro women in both bonding and bridging relations in times of need. Moreover, the culture stresses the obligations of olla ${ }^{6}$ to solve the problems of neighbouring households, by mobilizing existing resources to secure survival. This strong sharing culture has kept marro continuing even when resources are limited, which is a good opportunity for future development of the relationship. However, 
following increases in drought, as indicated in group interviews, the number of people demanding help is increasing while resources to be shared are diminishing. This threatens the potential of marro in ensuring household food security. Moreover, lack of adequate external support combined with increases in livestock prices and the commoditisation of milk is also limiting the risk-pooling capacity of marro. The milk investment in marro has decreased following commoditisation of milk as indicated in all focus group discussions. Similarly, the discussants revealed that following increases in the price of livestock, many prefer to sell the livestock rather than slaughtering, which effectively limits sharing of meat and bone in marro relationships. These actions limit the role marro plays in building household food security that in long run may cause erosion of marro; this could adversely affect women and their households. Therefore, attention must be paid to the marro relationsship in order to expand its risk-pooling capacity for the benefit of the women and the households they manage.

\section{Conclusions}

This paper analysed the role of Borana women's indigenous social network, known as marro, in enhancing household food security. The study was carried out in two communities with different production systems, namely pastoral and agro-pastoral. In addition to livelihood, women's age and economic status were used to examine women's participation, resources shared and the role these resources have on household food security. The paper establishes that marro is a network in which all women participate regardless of differences in their production system, age and economic status. The majority of women participate occasionally in marro, whereas a significant number of poor and aged women use marro for daily survival.

Marro is established at different levels between neighbouring households and between distant households in separate locations, which are engaged in different production systems. The former marro has the bonding nature of a social security network that mobilizes existing resources in a village. The latter marro, considered as a bridging relation, is established between households in different livelihood systems to mobilize and share resources in different locations for survival. In both bonding and bridging relations, women share various types of resources categorized as food items, labour and cash. Food items are the most frequently shared in marro, aimed to overcome household food shortages. Although women share food items in normal circumstances, sharing increases during drought. Thus, marro as a social security network is playing a vital role in improving household food security. However, the low external attention given to this institution, combined with lack of resources and increased number of poor people in the area, is challenging the roles marro play in building household food security.

The findings of this study shed light on the roles social security networks play to overcome food shortage. These networks are vital in designing equitable and sustainable food security projects and programmes in pastoral areas in general and Borana area in particular.

\section{Endnotes}

${ }^{1}$ Busagonfa is a clan-based institution by which Borana pastoralists respond to serious economic problems of their clan members.

${ }^{2} \mathrm{Afan}$ Oromo is a language that belongs to the Cushitic family, spoken by the Oromo people.

${ }^{3}$ Toltu afan oromo word for someone who likes giving.

${ }^{4} \mathrm{Hamtu}$ is someone who does not like giving.

${ }^{5}$ Boran is an individual in the Borana society.

${ }^{6} \mathrm{Olla}$ is the people living in the same village or known as villagers.

\section{Acknowledgements}

The authors are grateful to Professor Gufu Oba for valuable comments. Special thanks to the Borana women who volunteered the information for this study. We are also thankful to Boru Daniel and Jarso Jaldessa for their help during the data collection.

\section{Funding}

This work was done through financial support from the Norwegian Ministry of Foreign Affairs - NORAD project institutional collaboration between Hawassa University, Ethiopia, and Norwegian University of Life Sciences, Norway.

Authors' contributions

AEA collected the data and drafted the manuscript. DJK provided the theoretical inputs and revised the paper. All authors read and approved the manuscript.

\section{Authors' information}

Abiyot Eliyas Anbacha is a Doctoral Fellow at the Department of International Environment and Development Studies, Norwegian University of Life Sciences (NMBU).

Darley Jose Kjosavik is a Professor of International Development Studies at the Department of International Environment and Development Studies, Norwegian University of Life Sciences (NMBU).

\section{Competing interests}

The authors declare that they have no competing interests.

\section{Publisher's Note}

Springer Nature remains neutral with regard to jurisdictional claims in published maps and institutional affiliations.

Received: 1 December 2017 Accepted: 30 May 2018

Published online: 25 October 2018

References

Abebe, D., 2016. Resilience and Risk in Borana Pastoral Areas of Southern Ethiopia: Recent Trends in Diversified and Alternative Livelihoods, USAID/East Africa Resilience Learning Project, Tufts University, US. https://pdf.usaid.gov/ pdf_docs/pa00m1pz.pdf. 
Agrawal, Arun, Kononen, Minna, and Perrin, Nicolas (2009), The role of local institutions in adaptation to climate change. Paper no. 118: Social development working papers.

Aktipis, C. Athena, Lee Cronk, and Rolando de Aguiar. 2011. Risk-pooling and herd survival: An agent-based model of a Maasai gift-giving system. Human Ecology 39: 131-140.

Aldrich, Daniel P., and Michelle A. Meyer. 2015. Social capital and community resilience. American Behavioral Scientist 59 (2): 254-269.

Aldrich, Daniel P., Page, Courtney, and Paul, Christopher J. (2016), Social capital and climate change adaptation.

Bassi, Marco, and Boku Tache. 2007. Governance and ecosystem management for the conservation of biodeversity, Case study report on Borana-Oromo community conserved landscapes. Ethiopia: CENESTA.

Brunie, Aurélie. 2009. Meaningful distinctions within a concept: Relational, collective, and generalized social capital. Social Science Research 38 (38): 251-265.

Coppock, D. Layne. 1994. The Borana plateau of southern Ethiopia: Synthesis of pastoral research, development and change, 1980-91. Addis Ababa: International Livestock Center for Africa.

Desta, Solomon, and D. Layne Coppock. 2004. Pastoralism under pressure: Tracking system change in southern Ethiopia. Human Ecology 32 (4): 465486.

Devereux, Stephen, and Melese Getu. 2013. The conceptualisation and status of informal and formal social protection in sub-Saharan Africa. In Informal and formal social protection systems in sub-Saharan Africa, ed. Stephen Devereux and Melese Getu, 1-7. Ethiopia: Organi-sation for Social Research in Eastern and Southern Africa.

Dhal G. \& Hjort A. 1979. Pastoral change and role of drought. SAREC report, Swedish Agency for Research Cooperation with Develping Countries. Stockholm. https://onlinelibrary.wiley.com/doi/full/10.1111/j.1467-7717.1992. tb00385.x.

Granovetter, Mark S. 1973. The strength of weak ties. American Journal of Sociology 78 (6): 1360-1380.

Gray, Clark, and Valerie Mueller. 2012. Drought and population mobility in rural Ethiopia. World Development 40 (1): 134-145.

Hertkorn, Marie-Luise, Hassan Roba, and Brigitte Kaufmann. 2015. Borana women in livestock management: Roles, perceptions, recent changes. Nomadic peoples 19: 30-52

Johnson, R.B. 1999. Social networks and exchange. In Turkana herders of dny savanna: Ecology and biobehavioural response of nomads to an uncertain environment, ed. A.M. Little and W.P. Leslie. New York: Oxford University Press.

Kazianga, Harounan, and Christopher Udry. 2006. Consumption smoothing? Livestock, insurance and drought in rural Burkina Faso. Journal of Development Economics 79 (2): 413-446.

Khalif, Zeinabu Kabale. 2010. Pastoral transformation: Shifta-war, livelihood, and gender perspectives among the Waso Borana in Northern Kenya. Norway: Norwegian University of Life Sciences.

Moser, Caroline. 1998. The asset vulnerability framework: Reassessing urban poverty reduction strategies. World Development 26 (1): 1-19.

Moser, Caroline, et al. (2010) Pro-poor adaptation to climate change in urban centers: Case studies of vulnerability and resilience in Kenya and Nicaragua, 54947-GLB (updated June).

Newman, L. L., and D. A. 2005. Network structure, diversity, and proactive resilience building: a response to Tompkins and Adger. Ecology and Society 10(1): r2. https://www.ecologyandsociety.org/vol10/iss1/resp2/.

Oba, Gufu. 2001. The importance of pastoralists' indigenous coping strategies for planning drought management in the arid zone of Kenya. Nomadic Peoples 5 (1): 89-119.

Ostrom, Elinor, and T.K. Ahn. 2001. A social sciences perspective on social capital: Social capital and collective action, European research conference on "social capital: Interdisciplinary perspectives,", 15-20. Exeter: United Kingdom.

Pelling, Mark, and Chris High. 2005. Understanding adaptation: What can social capital offer assessments of adaptive capacity? Global Environmental Change 15: 308-319.

Platteau, Jean-Philippe. 1991. Traditional systems of social security and hunger insurance: Past achievements and modern challenges. In Social security in developing countries, ed. Ehtisham Ahmad et al. Oxford Scholarship Online. Clarendon, Oxford.

Potkanski, T. 1999. Mutual assistance among the Ngorongoro Maasai. In The poor are not us: Poverty and pastoralism in Eastern Africa, ed. David Anderson and Vigdis Broch-Due. Oxford: James Currey East African studies.
Putnam (1993), Making democracy work eds Robert Leonardi and Raffaella Y. Nonetti Civic traditions in modern Italy; United Kingdom: Princeton University Press.

Putnam. 2000. Bowling alone: The collapse and revival of American community. New York: Simon and Schuster, New York.

Sato, Shun. 1984. The Rendille subsistence groups based on age-system. African Study Monographs, Supplementary Issue 3: 45-57.

Sato, Shun. 1997. How the East African pastoral nomads, especially the Rendille, respond to the encroaching market economy. African Study Monographs 18 $(3,4): 121-135$

Scott, James C. 1976. The moral economy of the peasant rebellion and subsistence in Southeast Asia. UK: Yale University press.

Stavropoulou, Maria, Rebecca Holmes, and Nicola Jones. 2017. Harnessing informal institutions to strengthen social protection for the rural poor. Global Food Security 12: 73-79.

Tache, Boku, and Gufu Oba. 2008. Linkages between land use changes, dought impacts and pastoralists livelihood responses in Borana southern Ethiopia. Norwegian University of Life Science.

Tache, Boku, and Espen Sjaastad. 2008. Mutual assistance and poverty reduction among Borana Oromo: The Institution of Buusaa Gonofaa. Norwegian University of Life Sciences.

Tiki, Waktole, Gufu Oba, and Terje Tvedt. 2010. Human stewardship or ruining cultural landscapes of the ancient Tula wells, southern Ethiopia. The Geographical Journal 10: 1475-4959.

Tolossa, Degefa. 2009. An assessment of the role of local institutions and social capital in household food security: A case study at two rural communities in Oromiya Zone, Amhara Region. In Proceedings of the 16th International Conference of Ethiopian Studies, ed. Svein Ege et al. Trondheim. Trondheim: NTNU-trykk. http://portal.svt.ntnu.no/sites/ices16/Proceedings/Volume\%203/ Degefa\%20Tolossa\%20-

\%20An\%20Assessment\%20of\%20the\%20Role\%20of\%20Local\%20Institutions. pdf

Vries, Danny, Paul W. Leslie, and J.Terrence McCabe. 2006. Livestock acquisitions dynamics in nomadic pastoralist herd demography: A case study among Ngisonyoka herders of South Turkana, Kenya. Human Ecology 34 (1): 1-25.

Woolcock, Michael. 2001. The place of social capital in understanding social and economic outcomes. Canadian Journal of Policy Research 2 (1): 11-17.

\section{Submit your manuscript to a SpringerOpen ${ }^{\odot}$ journal and benefit from:}

- Convenient online submission

- Rigorous peer review

- Open access: articles freely available online

High visibility within the field

Retaining the copyright to your article

Submit your next manuscript at $>$ springeropen.com 